\title{
PEMBUATAN MEDIA PEMBELAJARAN COMPACT DISC (CD) INTERAKTIF MENGGUNAKAN ADOBE FLASH PADA PEMBELAJARAN IPA MATERI POKOK RESPIRASI KELAS VII SMP NEGERI 12 BATAM
}

\section{COMMITTING INTERACTIVE INSTRUCTIONAL MEDIA "COMPACT DISC (CD) USING ADOBE FLASH ON RESPIRATION MATTER OF SCIENCE SUBJECT ATCLASS VII SMPN 12 BATAM}

\author{
Niadaniati Sitanggang ${ }^{1}$, Nurhaty Purnama Sari ${ }^{2 *}$, Fenny Agustina ${ }^{3}$ \\ ${ }^{123}$ Program Studi Pendidikan Biologi, FKIP, Universitas Riau Kepulauan, Batam \\ *Koresonden: nurhatypurnamasari@gmail.com
}

\begin{abstract}
Abstrak
Jenis penelitian ini adalah Penelitian dan Pengembangan $(R \& D)$, merupakan metode untuk menghasilkan produk tertentu dimana model pengembangan yang digunakan adalah model prosedural yang bersifat deskriptif dengan materi pokok respirasi. Pengumpulan data dilakukan dengan menggunakan angket. Teknik analisis data menggunakan pendekatan deskriptif kualitatif dan uji coba instrumen angket dilakukan oleh ahli media, ahli materi dan respon pemakaian media oleh peserta didik. Berdasarkan hasil analisis data dari kelayakan menurut ahli media pembelajaran dengan persentase total sebesar $85 \%$, ahli materi dengan persentase total $86,11 \%$, hasil uji coba pada peserta didik dengan persentase total sebesar $88,01 \%$. Sehingga hasil pengujian rata-rata keseluruhan adalah 86,37\%. Berdasarkan hasil tersebut dapat disimpulkan bahwa media pembelajaran dengan menggunakan adobe flash termasuk kriteria layak sebagai media dalam pembelajaran materi respirasi.
\end{abstract}

Kata Kunci: Penelitian dan Pengembangan, Media Pembelajaran, CD Interaktif, Respirasi.

\begin{abstract}
The type of this research was the Research and Development $(R \& D)$, it was a method with aim to produce a particular product, and development model used was a descriptive procedural model on respiration subject matter. The data collection was done by using questionnaire. Data were analyzed using qualitative descriptive approach and questionnaire testing was conducted by media experts, subject matter experts and learners' media usage response. Based on the eligibility data by media experts was $85 \%$, a material experts was $86.11 \%$, and the results by learners' media usage response was $88.01 \%$. So the Overall assessment was $86.37 \%$. Based on these results it can be concluded that the instructional media by using adobe flash media categorized as an eligible learning media on respiration subject matter.
\end{abstract}

Keywords: Research and Development, Instructional Media, Interactive CD, Respiration.

\section{PENDAHULUAN}

Perubahan global dalam perkembangan pengetahuan dan teknologi yang cukup pesat berimbas pada pola hidup manusia.Hal ini dapat dilihat dari munculnya berbagai produk teknologi yang mampu mendukung kegiatan manusia dalam memenuhi kebutuhan hidupnya agar lebih mudah dan cepat, misalnya dengan adanya computer, televisi, handphone dan sebagainya. Khususnya pada perkembangan teknologi computer pada saat ini telah ditemukan software-sofware yang dapat menampilkan teks, suara, grafis, dan animasi sehingga diperoleh sebuah karya aplikasi multimedia yang dapat menarik 
perhatian orang untuk menyimaknya. Perkembangan teknologi tersebut salah satunya juga berimbas pada sistem pendidikan, salah satunya perkembangan media pembelajaran. Media pembelajaran yang pada mulanya hanya berbentuk teks dan grafik saja saat ini telah berkembang menjadi sebuah media pembelajaran yang dapat memadukan teks, suara, grafis, video, dan animasi yang menarik untuk dipelajari.

Pendidikan sangat berpengaruh terhadap suatu kemajuan dan perkembangan suatu bangsa, dimana pendidikan merupakan sarana dan wahana yang strategis di dalam pengembangan sumber daya manusia. Oleh karena itu pendidikan harus mendapat perhatian yang lebih. Berbagai usaha telah dilakukanoleh pengelola pendidikan untuk mengembangkanpendidikan di negara ini dalamrangka meningkatkan prestasi belajar peserta didik dengan mengoptimalkan sumber-sumber daya pendidikan yang tersedia.

Pembelajaran Ilmu Pengetahuan Alam (IPA) pada jenjang SMP/MTs menekankan pada pemberian pengalaman belajar secara langsung melalui penggunaan dan pengembangan keterampilan proses dan sikap Ilmiah (Depdiknas,2007). Pembelajaran IPA pada jenjang SMP masih banyak mengalami hambatan-hambatan, diantaranya dalam pembelajaran IPA disekolah, terdapat konsep yang mengandung materi-materi yang tidak mudah ditemui secara langsung dalam kehidupan sehari-hari.Hal ini menyebabkan peserta didik kesulitan dalam memahami materi secara konseptual. Konsep materi IPA pada umumnya mengandung hal-hal yang bersifat abstrak sehingga pendidik pun seringkali kesulitan untuk menyampaikan materi tersebut secara verbal (Widiastusi, 2010).

Berdasarkan hasil wawancara dengan guru IPA SMP N12 Batam peserta didik masih banyak kesulitan memahami proses fisiologi yang terjadi pada makhluk hidup, yaitu pada materi respirasi pada manusia. Materi tersebut sulit dipahami karena tidak dapat diamati secara langsung. Untuk itu agar peserta didik lebih mudah memahami pelajaran materi respirasi pada manusia perlu adanya sumber media pembelajaran dalam bentuk CD interaktif yang menampilkan teks, gambar, animasi, suara, dan vidio yang dapat menarik perhatian serta menciptakan suasana menyenangkan bagi peserta didik, guna memenuhi atau melengkapi variasi sumber belajar peserta didik di sekolah ataupun sebagai sumber belajar mandiri. Guru sebagai tenaga pendidik masih banyak yang belum memanfaatkan pembuatan media pembelajaran yang berbasis Informasi Teknologi (IT).

Media pembelajaran interaktif yang dapat digunakan dalam pembelajaran adalah dalam bentuk CD pembelajaran.CD interaktif merupakan media yang dapat 
merangsang aktivitas peserta didik untuk mempelajari suatu materi pembelajaran. Adobe Flash merupakan software yang tepat untuk membuat berbagaibentuk sajian visual yang dapat mengintepretasikan berbagai media, seperti video, animasi, gambar dan suara. Penggunaan multimedia interaktif dengan Adobe Flash dalam pembelajaran diharapkan mampu menjadikan pembelajaran IPA lebih bervariasi danmendapatkan respon positif dari peserta didik serta memfasilitasi kemampuan memahami materi yang diajarkan oleh guru.

Uraian di atas menarik perhatian penulis dan melatar belakangi penulis untuk melakukan penelitian pembuatan media pembelajaran $\mathrm{CD}$ interaktif menggunakan adobe flash pada pembelajaran IPA materi pokok respirasi kelas VII SMP Negeri 12 Batam.

\section{METODOLOGI}

Penelitian ini adalahjenis penelitian Research and Development $(R \& D)$ yang merupakan desain penelitian dan pengembangan, yaitu metode penelitian yang digunakan untuk menghasilkan produk tertentu dan menguji keefektifan produk tersebut (Sugiyono 2014). Jenis data pada penelitian ini menggunakan data kualitatif dan kuantitatif. Data kualitatif sebagai data pokok dengan menggunakan angket yang berupa penilaian kelayakan media pembelajaran CD interaktif oleh para ahli media, ahli materi dan siswa dengan skala penilaian 1 sampai 4 . Dimana 4 = layak/sangat setuju, $3=$ cukup layak/ setuju, 2 = tidak layak/ tidak setuju, 1 = sangat tidak layak/ sangat tidak setuju. Data tersebut memberi gambaran mengenai kelayakan program yang dikembangkan.Dan data kuantitatif yang diperoleh dari pengisian skor pada angket oleh validator dan peserta didik.

Instrumen pengumpulan data dalam penelitian ini adalah dengan menggunakan instrument angket (Qusioner), yang bersifat tertutup. Angket ini digunakan untuk mengetahui pendapat responden terhadap pengembangan media pembelajaran berupa CD interaktif.

Setelah data diperoleh, selanjutnya adalah menganalisis data tersebut. Penelitian ini lebih menitikberatkan pada bagaimana membuat media pembelajaran CD interaktif, sehingga data dianalisis dengan statistik deskriptif persentase. Adapun langkah-langkah yang digunakan untuk mengolah data adalah sebagai berikut :

a. Mengkuantitatifkan jawaban hasil angket sesuai dengan indikator yang telah ditetapkan dengan memberikan skor sesuai dengan bobot yang telah ditentukan sebelumnya. 
b. Membuat tabulasi data.

c. Menghitung data persentase dari angket tiap-tiap item

$$
P=\frac{X}{X_{1}} x 100 \%
$$

Dimana :

$$
\begin{array}{ll}
\mathrm{P}(\mathrm{s}) & : \text { persentasi komponen } \\
\mathrm{X} & : \text { jawaban respon dalam satu item } \\
\mathrm{X}_{1} & : \text { jumlah nilai ideal dalam satu item }
\end{array}
$$

(Widoyoko, 2013)

d. Menghitung data persentase dari ahli media, ahli materi dan peserta didik (Widoyoko, 2013 ) dengan rumus :

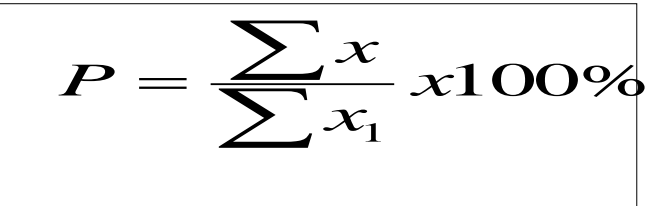
Keterangan :
$\mathrm{P}$
: Persentase
$\sum \mathrm{X}$
: Jumlah keseluruhan jawaban responden
$\sum \mathrm{X}_{1}$
: Jumlah keseluruhan nilai ideal dalam satu item
$100 \%$
: Konstanta

Dari persentasi yang telah diperoleh kemudian ditransformasikan kedalam tabel supaya pembacaan hasil peneliitian menjadi mudah. Untuk menentukan kriteria kualitatif dilakukan dengan cara :

a. Menentukan persentase skor ideal ( skor maksimum $)=100 \%$

b. Menentukan persentase skor terendah ( skor minimum $)=0 \%$

c. Menentukan interval yang dikehendaki $=4$ ( Layak/ Valid $=4$, Cukup layak/ Cukup valid $=3$, Tidak layak/ Tidak valid $=2$, Sangat tidak layak/ Sangat tidak valid $=1$ )

d. Menentukan range $=100-0=100$

e. Menentukan lebar interval $(100 / 4=25)$

Berdasarkan perhitungan diatas, maka range persentase dan kriteria kualitatif dapat ilustrasikan pada Gambar 1 sebagai berikut :

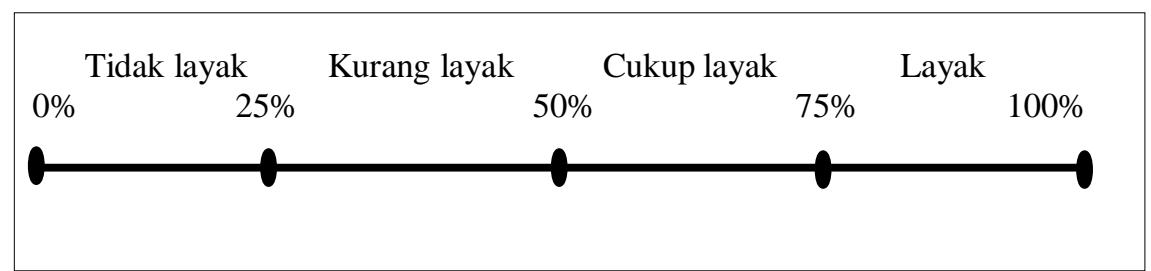


Gambar 1. Skor Kriteria Kualitatif (Sugiyono, 2012)

Berdasarkan skor kriteria kualitatif pabila dilihat dari tingkat kelayakannya dapat disajikan pada Tabel 1sebagai berikut :

Tabel $1:$ Kriteria tingkat kelayakan

\begin{tabular}{|c|c|c|c|c|}
\hline KATEGORI & PERSENTASE & KUALIFIKASI & EKUIVALEN & KETERANGAN \\
\hline 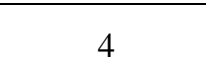 & $76-100$ & Valid & Layak & $\begin{array}{l}\text { Digunakan tanpa } \\
\text { revisi }\end{array}$ \\
\hline 3 & $51-75$ & Cukup valid & Cukup layak & $\begin{array}{l}\text { Digunakan,denga } \\
\mathrm{n} \text { revisi kecil }\end{array}$ \\
\hline 2 & $26-50$ & Krang valid & Kurang layak & $\begin{array}{l}\text { Tidak dapat } \\
\text { digunakan }\end{array}$ \\
\hline 1 & $0-25$ & Tidak valid & Tidak layak & $\begin{array}{l}\text { Sama sekali tidak } \\
\text { dapat digunakan }\end{array}$ \\
\hline
\end{tabular}

\section{PEMBAHASAN}

Tahap pengujian media pembelajaran CD interaktif pembelajaran IPA dilakukan dengan melakukan validasi media terdiri dari ahli media pembelajaran, ahli materi dari dosen ahli materi pembelajaran.

Tabel 2. Penilaian Ahli Media Pembelajaran

\begin{tabular}{clccc}
\hline No. & Aspek Penilaian & Skor & Skor yang Diharapkan & Prosentase (\%) \\
\hline 1 & Efektifitas & 13 & 16 & 81 \\
2 & Tampilan & 24 & 28 & 85 \\
3 & Efisien & 14 & 16 & 87 \\
\hline
\end{tabular}


SIMBIOSA Vol 5 (2): 91-98 Desember 2016

Niadaniati Sitanggang, Nurhaty Purnama Sari, Fenny Agustina : Pembuatan media....

Tabel 3. Penilaian Ahli Meteri Pembelajaran

\begin{tabular}{ccccc}
\hline No. & Aspek Penilaian & Skor & Skor yang Diharapkan & Prosentase (\%) \\
\hline 1 & Kesesuaian isi Materi & 85 & 96 & 88,54 \\
2 & Kesesuaian pembelajaran & 70 & 84 & 83,33 \\
\hline & Jumlah & $\mathbf{1 5 5}$ & $\mathbf{1 8 0}$ & $\mathbf{8 6 , 1 1}$ \\
\hline
\end{tabular}

Tabel 4. Penilaian Ujicoba Produk pada Peserta Didik

\begin{tabular}{ccccc}
\hline No. & Aspek Penilaian & Skor & Skor yang Diharapkan & Prosentase (\%) \\
\hline 1 & Efek pembelajaran & 974 & 1116 & 87,28 \\
2 & Kemenarikan Media & 663 & 744 & 89,11 \\
\hline & Jumlah & $\mathbf{1 6 3 7}$ & $\mathbf{1 8 6 0}$ & $\mathbf{8 8 , 0 1}$ \\
\hline
\end{tabular}

Tabel 5. Prosentase Keseluruhan Hasil Penilaian Terhadap Media Pembelajaran

\begin{tabular}{clccc}
\hline No. & Responden & $\begin{array}{c}\text { Persentase } \\
\text { Rata-rata }(\boldsymbol{\%})\end{array}$ & Kualifikasi & Ekuivalen \\
\hline 1 & Ahli Media & 85,00 & Valid & Layak \\
2 & Ahli Materi & 86,11 & Valid & Layak \\
3 & Peserta didik & 88,01 & Valid & Layak \\
\hline & Rata-rata & $\mathbf{8 6 , 3 7}$ & Valid & Layak \\
\hline
\end{tabular}

\section{PEMBAHASAN}

Berdasarkan hasil uji coba yang telah dilakukan, menyatakan bahwa media pembelajaran menggunakan CD interaktif dapat dimanfaatkan sebagai media pembelajaran IPA pada materi respirasi utuk kelas VII Sekolah Menengah Pertama (SMP). CD interaktif ini mudah digunakan dengan adanya tombol bantuan pada CD interaktif. Kriteria penilaian terlihat bahwa komponen media, keefektifan media sebesar $81 \%$ masuk dalam kategori layak, tampilan media sebesar $85 \%$ masuk dalam kategori layak, keefisienan media sebesar $87 \%$ masuk dalam kategori layak. Dilihat dari komponen materi, kesesuaian isi materi persentasi yang didapat sebesar 88,54\% termasuk dalam kategori layak, kesesuaian strategi pembelajaran sebesar 83,33 \% termasuk kategori layak. Dilihat dari pengguna produk pun telah memenuhi syarat kelayakan dapat dilihat dari kriteria efek pembelajaran sebesar 87,28\%, dapat menarik perhatian peserta didik sebesar 89,11\% . Maka dari hasil uji coba produk tersebut, media pembelajaran menggunakan CD interaktif IPA yang dikembangkan, layak dijadikan sebagai media media pembelajaran IPA pada materi respirasi pada jenjang Sekolah Menengah Pertama Negeri. 
Penelitian Khikmah (2013) dengan judul Pengembangan Media CD Interaktif Materi Sruktur dan Fungsi Sel dilengkapi Teka-teki Silang Berbasis Flash, menunjukkan bahwa Media pembelajaran CD interaktif materi struktur dan fungsi sel dilengkapi tekateki silang berbasis flash efektif terhadap aktivitas dan hasil belajar peserta didik. Diharapkan dengan menggunakan media pembelajaran berupa CD interaktif, dapat memberikan variasi dalam proses pembelajaran serta menarik minat peserta didik terutama minat dalam proses belajar dan pembelajaran. Lebih lanjut bahwa manfaat yang dapat diperoleh adalah proses pembelajaran ini sangat menyenangkan, dapat merangsang perhatian peserta didik untuk ikut terlibat aktif dalam pembelajaran, dapat menarik keingintahuan peserta didik dalam memahami dan memecahkan suatu masalah, aktivitas belajar peserta didik dapat ditingkatkan dan efektif terhadap hasil belajar peserta didik sesuai dengan tujuan pembelajaran (Khikmah, 2013).

\section{KESIMPULAN DAN SARAN}

Kesimpulan

Dari hasil penelitian pengembangan yang telah dilakukan dapat diambil kesimpulan, sebagai berikut :

1. Produk yang telah dihasilkan berupa CD interaktif IPA yang materi respirasi melalui prosedur pengembangan dapat menjadi media sumber pembelajaran yang dihasilkan berbentuk CD (Compact Disk) dengan menggunakan adobe flash, memiliki komponen berupa animasi video, suara, gambar, dan teks yang menjadikan sumber belajar ini menjadi menyenangkan.

2. Dari hasil uji coba media pembelajaran yang dikembangkan dapat layak digunakan sebagai media pembelajaran.

Saran

Penelitian ini termasuk penelitian pengembangan sumber belajar IPA yaitu; a) pengembangan produk lebih lanjut adalah peningkatan kualitas produk melalui pada tahap perencanaan media pembelajaran dengan alur kerja yang baik dan sesuai dengan konsep pembelajaran serta sesuai dengan strategi pembelajaran yang direncanakan; dan b) Saran pemanfaatan bahwa CD Pembelajaran Interaktif ini dapat digunakan sebagai salah satu sumberbelajar bagi siswa baik di sekolah maupun di rumah secara mandiri serta dapat digunakan sebagai media pendukung, bagi guru untuk menjelaskan materi di 
dalam kelas dengan menggunakan berbagai macam metode pembelajaran.

\section{REFERENSI}

Arsyad, A. 2014. Media Pembelajaran. Raja Grafindo Persada. Jakarta.

Astuti. 2012. Pengembangan Media Pembelajaran dengan Multimedia Interaktif Menggunakan Adobe Flash CS3 untuk Mempasilitasi Kemampuan Pemecahan Masalah pada Pembelajaran Matematika SMP Kelas VIII (Skripsi). Universitas Islam Negeri Sunan Kalijaga. Yogyakarta.

Khikmah . 2013. Pengembangan Media CD Interaktif Materi Sruktur dan Fungsi Sel dilengkapi Teka-teki Silang Berbasis Flash( Skripsi). Universitas Negeri Semarang. Semarang.

Setyosari.2013. Metode Penelitian Pendidikan \& Pengembangan. Kencana Prenadamedia Group. Jakarta.

Widoyoko, 2013.Teknik Penyusunan Istrumen Penelitian. Pustaka Pelajar. Yogyakarta.

Sudjana, N dan Rivai, A. 2009. Media Pengajaran. Sinar Baru Algensindo. Bandung.

Sunyoto A. 2010. Adobe Flash $+X M L=$ Rich Multimedia Application, ANDI, Yogyakarta.

Sutjiono TWA. 2005. Pendayagunaan media pembelajaran. Jurnal Pendidikan Penabur 4 (4):76-84.

Sardiman AM. 2014. Interaksi dan Motivasi Belajar Mengajar . Rajawali Pers. Jakarta.

Warsita B. 2008. Teknologi Pembelajaran, Landasan dan Aplikasinya. PT Rineka Cipta. Jakarta.

Wibawanto W. 2006.Membuat Game dengan Macromedia Flash.Yogyakarta. 